\title{
Effects of a Short Online Mindfulness Intervention on Relationship Satisfaction and Partner Acceptance: the Moderating Role of Trait Mindfulness
}

\author{
Gesa Kappen ${ }^{1}$ (D) Johan C. Karremans ${ }^{1}$ - William J. Burk ${ }^{1}$
}

Published online: 2 July 2019

(C) The Author(s) 2019

\begin{abstract}
Objectives Recently, researchers have started to investigate the potential interpersonal effects of mindfulness in the context of romantic relationships. However, most of these studies have focused on trait mindfulness and its association with relationship outcome measures. We employed a randomized, controlled design to investigate the effects of mindfulness practice on relationship quality. We also explored the role of partner acceptance as a possible mechanism of change and investigated whether baseline levels of trait mindfulness would moderate intervention effects.

Methods One hundred and thirteen participants in a romantic relationship ( $89 \%$ women; $M_{\text {age }}=27.27$ years, $S D=8.31$ years) living in the Netherlands participated in either a low-dose, online mindfulness-based intervention or a psycho-education control intervention for 12 days.

Results Results indicated that general relationship satisfaction and partner acceptance increased for both conditions $\left(F_{\text {satisfaction }}(1,93)=5.94, \eta_{\text {partial }}^{2}=0.06, p=0.017 ; F_{\text {acceptance }}(1,93)=4.63, \eta_{\text {partial }}^{2}=0.05, p=0.034\right)$. Among participants with relatively low baseline levels of trait mindfulness, relationship satisfaction improved more so in the mindfulness than that in the control condition (trait mindfulness $\times$ condition: $B=0.34, S E=0.15, \beta=0.40, p=0.024$ ).

Conclusions Short, online, self-administered mindfulness-based interventions may positively impact romantic relationship quality and might be particularly effective for participants with low levels of trait mindfulness. Theoretical and practical implications are discussed.
\end{abstract}

Keywords Mindfulness · Decentering · Intervention · Online-based · Romantic relationships · Relationship satisfaction · Partner acceptance $\cdot$ Randomized-controlled $\cdot$ Active control $\cdot$ Psycho-education

Mindfulness has often been defined as a state of mind qualified by deliberate attention to present-moment experiences with an open and non-judgmental stance (Kabat-Zinn 1990) and has received abundant theoretical and empirical attention in the past decade. Bringing mindful attention to everyday experiences is considered an inherent human capacity, which differs between individuals, meaning that some people naturally bring mindful attention to their experiences more often

Gesa Kappen

g.kappen@psych.ru.nl

1 Behavioural Science Institute, Radboud University Nijmegen, Nijmegen, the Netherlands than others (referred to as trait mindfulness; e.g., Baer et al. 2006; Brown and Ryan 2003). Higher levels of trait mindfulness have been associated with positive emotional states, reduced stress, and psychological health in general (Bravo et al. 2016; Brown and Ryan 2003; Weinstein et al. 2009). To improve people's ability to be mindful in their daily lives, a number of interventions have been developed, referred to as mindfulness-based interventions (MBIs). Whereas the first MBI was originally developed to alleviate chronic pain (mindfulness-based stress reduction; MBSR; Kabat-Zinn 1982), a substantial amount of studies have shown that the application of MBIs is much broader, ranging from the reduction of anxiety and depressive symptoms to improved cognitive functioning and increased general well-being, in both clinical and non-clinical populations (Chiesa and Serretti 2009; Grossman et al. 2004; Keng et al. 2011). These benefits may 
indeed follow from improvements in trait mindfulness as a result of MBIs (e.g., Carmody et al. 2008; Shahar et al. 2010).

MBIs vary greatly in modes of delivery (group, individual, online, face-to-face), length of exercises (3 to $45 \mathrm{~min}$ ) and total length (one time, 10 days, 8 weeks; Heppner and Shirk 2018; Van Dam et al. 2017). Preliminary studies indicated that even short inductions of mindfulness or very brief interventions delivered via websites or mobile applications could improve well-being (Economides et al. 2018; Heppner and Shirk 2018; Howells et al. 2016; Lebois et al. 2015; for a metaanalysis, see Spijkerman et al. 2016). Due to the popularization of mindfulness in recent years, these brief online interventions have become widespread in the general public, yet, still little is known about their effects in non-clinical samples (Heppner and Shirk 2018). The common aspect of MBIs is that states of mindfulness are induced by means of meditation exercises during which participants practice deliberate, nonjudgmental awareness of both internal processes (thoughts, emotions, bodily sensations) and external stimuli (e.g., sounds, smells, touch).

While most research has focused on the role of mindfulness in individual functioning and well-being, recent studies have suggested that the effects of mindfulness may extend beyond the individual. In addition to improvements between parents and their child (Singh et al. 2010), and therapists and their patients (Grepmair et al. 2007; Ryan et al. 2012), an increasing amount of studies have investigated whether mindfulness may promote the functioning and well-being of romantic relationships (Karremans et al. 2017). Most of these studies conducted so far, however, have focused on levels of trait mindfulness and their association with a variety of relationship outcome measures (see for example Adair et al. 2017a; Dixon and Overall 2016; Kappen et al. 2018; Kimmes et al. 2017; Mcgill et al. 2016; Teper and Inzlicht 2013; Wachs and Cordova 2007).

As suggested in a recent review, mindfulness may improve romantic relationship functioning as it has been related to a variety of basic mechanisms that are vital for the functioning of romantic relationships (Karremans et al. 2017). For example, studies have associated mindfulness with higher levels of and improvement in emotion regulation (Arch and Craske 2006; Creswell et al. 2007; Goldin and Gross 2010), improved executive control (for a review, see Chiesa et al. 2011), and recognition of otherwise implicit, potentially relationshipdestructive impulses (Brown and Ryan 2003; Koole et al. 2009).

Indeed, mindfulness has been related to a number of outcomes and processes that promote romantic relationship functioning (Karremans et al. 2017). For example, trait mindfulness has generally been linked to secure attachment (Caldwell and Shaver 2013; Goodall et al. 2012; Kimmes et al. 2017). Also, studies have shown that trait mindfulness buffered the negative impact of insecure attachment on relationship anxiety, destructive behaviors, and even the risk of breaking up (Dixon and Overall 2016; Iida and Shapiro 2017; Saavedra et al. 2010). In the context of relationship conflict, studies found that trait mindfulness was related to better identification and communication of emotions, better conflict resolution and increased forgiveness, and lower distress levels after conflict (Barnes et al. 2007; Hertz et al. 2015; Karremans et al. 2019; Wachs and Cordova 2007). A recent dyadic diary study revealed that participants who experienced more state mindfulness during work time reported more happiness, which was in turn positively related to spouses' relationship satisfaction and negatively to spouse-reported work-family conflict (MontesMaroto et al. 2017). Findings from another dyadic study suggested that partners with higher levels of trait mindfulness were perceived by their partners to be more responsive and were themselves better at recognizing their partner's responsive behavior (Adair et al. 2017a). In line with such findings, several previous studies have found a more general association between trait mindfulness and relationship satisfaction (for a recent overview, see McGill et al. 2016).

As has recently been argued and demonstrated (Kappen et al. 2018), another relationship-specific mechanism by which mindfulness may promote relationship satisfaction is partner acceptance, a general attitude of acknowledging potential imperfections of a partner without feeling the urge to change the other (Kappen et al. 2018; Karremans et al. 2017). "Partner imperfection" should be understood as any kind of partner behavior or trait that renders a partner less ideal in the eyes of the individual and every now and then may trigger negative emotions. To be clear, we do not refer to inherently (psychologically or physically) damaging partner behaviors but to relatively innocuous, everyday behaviors that may occur in every healthy relationship (Kappen et al. 2018).

Why would mindfulness foster acceptance of these partner behaviors? To clarify this, first consider the opposite of a mindful state of mind: A mindless state of mind is characterized by immersion in emotions, which can intensify negative emotions (Ciesla et al. 2012). If the partner engages in some kind of potentially negative behavior that triggers negative emotions, an individual low in mindfulness may find it relatively difficult to acknowledge and accept such negative emotions and may find it difficult to accept that the partner triggers such emotions. As a result, there may be a greater tendency of wanting to change the partner's behavior (i.e., being unaccepting). In contrast, a mindful state of mind is characterized by a so-called decentered perspective on experiences, meaning that an individual observes their internal experiences (thoughts, emotions, physical sensations) without judgment as passing events in the mind, rather than identifying with and getting entangled in these experiences (Bishop et al. 2004; Safran and Segal 1990). In this way, emotions can dissipate naturally and romantic partners might be better able to accept that their significant other sometimes triggers irritation or 
other negative emotions (i.e., partner acceptance; for a similar reasoning, see Kappen et al. 2018).

Indeed, previous correlational findings indicated that levels of trait mindfulness were positively associated with levels of partner acceptance, which in turn were related to higher levels of relationship satisfaction (Kappen et al. 2018). Also, couple therapies that include aspects of mindfulness (e.g., integrative behavioral couple therapy; Jacobson et al. 2000; acceptance and commitment therapy; Hayes 2004) are based on the idea that acceptance of negative relationship experiences and acceptance of less-than-ideal and somewhat negative aspects of a partner can promote relationship quality and satisfaction.

While a growing body of research suggests that mindfulness is associated with better relationship functioning, almost all studies so far have examined this topic using crosssectional designs, meaning studies have focused on the associations between levels of trait mindfulness and measures of relationship functioning. While valuable, such findings do not allow drawing conclusions about whether the training and cultivation of mindfulness can affect romantic relationships. Explicitly practicing mindfulness skills, for example by engaging in regular meditation exercises with a nonjudgmental focus on private experiences (thoughts, emotions, bodily sensations, and their interaction), should increase an individuals' ability to relate to their day-to-day experiences in a more mindful manner. Indeed, previous research has demonstrated that daily mindfulness exercises can foster mindfulness skills (Carmody et al. 2008; Shahar et al. 2010). Most relevant to the current research, relatively brief periods of engaging in these exercises have shown to increase mindfulness skills (Alberts 2017) and may foster prosocial behavior (Lim et al. 2015; Yusainy and Lawrence 2015).

Carson et al. (2004) demonstrated that, as compared to a wait-list control condition, couples that followed an 8-week mindfulness-based couple intervention displayed increases in both relationship satisfaction and acceptance of one another. In addition to mindfulness meditation practice, however, the intervention included various other elements that may have accounted for increases in relationship satisfaction (such as loving-kindness meditation with a focus on the partner). Recently, Khaddouma et al. (2017) reported the results of a pilot study in which 20 romantically involved participants followed a mindfulness-based stress reduction (MBSR) training. The researchers found that participants' level of relationship satisfaction increased from before to after the training, and some facets of mindfulness (i.e., non-reactivity, acting with awareness) that increased following the training were associated with increases in the partner's relationship satisfaction. The study did not include a control condition, however.

Studies investigating the effects of mindfulness have been criticized for a lack of consideration of individual difference variables that might predict people's response to mindfulnessbased interventions (Farias and Wikholm 2016). Shapiro et al.
(2011) found that individuals with relatively high levels of trait mindfulness prior to an MBSR training reported stronger stress reduction, and stronger increases of empathy and subjective well-being, as compared to individuals low in trait mindfulness. The authors suggested that higher levels of trait mindfulness before the intervention may have facilitated the understanding of meditation instructions and helped participants persist in regular practice. This was supported by a recent study investigating adherence to an online mindfulness program, in which trait mindfulness emerged as the strongest predictor of how many meditation sessions participants followed (Forbes et al. 2018). It could also be argued, however, that especially those low in mindfulness would benefit most from a mindfulness intervention, simply because they have more to gain and may "need" more mindfulness in their daily lives to experience its potential benefits.

The empirical question we address here is whether practicing mindfulness for 2 weeks via an online program could have downstream consequences for the functioning of the romantic relationship. Using a randomized controlled design, we examined whether a 12-day daily mindfulness meditation intervention can increase overall relationship satisfaction from pre- to post-intervention as compared to a minimally active control condition. Moreover, as a potential mechanism, we explored whether an increase in relationship satisfaction would be accompanied by increases in partner acceptance. Finally, we explored the question for whom a brief mindfulness intervention would be effective in promoting relationship satisfaction, focusing on the role of pre-intervention levels of trait mindfulness.

\section{Method}

\section{Participants}

Participants were recruited in collaboration with a Dutch employment agency with an extensive and diverse pool of followers on several social media sites (www.inperson.nl). The study was advertised on the agency's Facebook and LinkedIn sites. The advertising text shortly stated the topic of the study (romantic relationships), duration (2 weeks), reward (taking part in a raffle for a trip to Paris for two), and requirements (minimal 18 years of age, minimal relationship length of 1 year). A hyperlink led to a subscription page providing more information about the researcher (to decrease anonymity and thus increase willingness to participate) and informed participants that, in addition to answering questions, they may have to do an exercise of $10 \mathrm{~min}$ every day. It was also announced that they would be paid a coupon of 15 Euros for participation and that they, only in case of daily completion, would take part in a raffle for a trip to Paris for two. A total of 184 eligible participants were called by phone and were then given information on the procedure 
and the possibility to ask questions. Commitment was checked by explicitly asking participants whether they would have the time and dedication to complete measures and possible exercises on a daily basis for the period of the study. It was also stressed that their participation was an important contribution to scientific research. Participants were not informed that the study concerned mindfulness. When the intervention started 2 weeks later, 118 participants had given informed consent and provided information on the pre-measures. Finally, at the end of the study, 100 participants also filled in the post-measures; the rate of dropout between filling in the pre-measures and the post-measures was thus $15 \%$. A series of $t$ tests and chi-square tests examined whether the 100 participants with complete information differed from the 18 that missed posttest measures. These analyses revealed that these two groups did not differ on any study measure or demographic variable (all $p>0.13$; except for a trend for relatively more males in the dropout group: $x^{2}(1)=3.38, p=0$. 067). For the final analyses, five participants were excluded due to scores of 3 or lower on a 7-point scale measuring how seriously they had completed the study (including these participants did not change the results). Analyses were conducted including the 18 participants that dropped out (intention to treat approach). The survey software had randomly allocated participants to either the mindfulness $(n=56)$ or the control condition $(n=57)$. Age ranged from 18 to 55 years $(M=27$. 27 years, $S D=8.31$ years). Most participants $(56.6 \%)$ indicated to have finished higher professional education, $29 \%$ obtained basic vocational education, and $14 \%$ had secondary education. Most participants were women (89\%). A total of $22 \%$ of the participants were married, $62 \%$ were living together, and $25 \%$ had children. Relationship duration ranged from 1 to 34 years ( $M=6.66$ years, $S D=7.16$ years). All participants were fluent in Dutch. Participants in the two conditions did not significantly differ on demographic variables (Table 1).

\section{Procedure}

The general procedure of the study was similar for participants in both conditions: One week after the completion of recruitment, all participants filled in baseline measures, including measures of trait mindfulness, relationship satisfaction, and partner acceptance (day 1). Then, from day 2 to day 13, participants completed online tasks for either the mindfulness or control intervention, once a day (5-15 min). On day 14, participants filled in post-intervention measures, including relationship satisfaction and partner acceptance. Completion of the study thus took 14 days in total, which is similar to other studies in which brief online MBIs have been found beneficial (approximately 2 weeks; e.g., Cavanagh et al. 2013; Economides et al. 2018; Glück and Maercker 2011; Howells et al. 2016; Hülsheger et al. 2013, 2015). All questionnaires and intervention materials were hosted by the online survey software qualtrics.com and were made available via a URL link (all surveys used can be found in the SM). Participants navigated through the materials at their own pace by mouse click. Links to these materials were sent in the morning via email, such that, as from 9:00 a.m., participants had access to the surveys and could chose independently when to complete them and thus (for the mindfulness condition) when to do the mindfulness exercise. To further increase responses, we sent reminder emails at 5:00 p.m., with the aim of still providing enough evening time to fill in the survey before going to bed.

Mindfulness Condition The mindfulness condition consisted of three components: (1) psycho-education, (2) daily registering the occurrence (or absence of) negative relationship experiences, and (3) a short, daily meditation exercise centering either on experiences in general or negative partner-related emotions, depending on whether or not a negative experience in the relationship had been reported in step 2 .

Control Condition The control condition consisted of two components: (1) psycho-education and (2) daily registering the occurrence (or absence of) negative relationship experiences. Participants in both conditions were provided with the same psycho-education material and were asked to register negative relationship experiences each day. The control condition thus only differed in that participants did not complete mindfulness exercises, allowing us to investigate the unique effect of daily mindfulness exercises.

Psycho-education On the first intervention day, participants in both conditions read a short text entitled "the automatic pilot." The text was based on the mindfulness-based stress reduction (MBSR) training protocol, explaining how an automatic way of acting and thinking could occasionally result in undesirable behavior or thoughts:

Sometimes, we can drive in our car for kilometers on end, being in a complete state of automatic pilot, without even being aware of what we do. In the same way, we are often not entirely present in the here-and-now of our daily lives: Sometimes we are very far away without knowing it. In some cases, it is very convenient that behavior is automated. Driving, writing, and making gestures are all examples of automatic behavior. However, in some cases automatisms can also lead to undesirable behavior, such as automatically reacting aggressively when we feel angry or automatically getting caught up in rumination when something troublesome has happened.

In each condition, participants then read a different description of how to break free from the automatic pilot: Participants in the mindfulness condition read that the exercises they would be doing during the study were a way of disengaging 
Table 1 Sample characteristics

\begin{tabular}{|c|c|c|c|c|c|}
\hline & \multicolumn{2}{|c|}{$\begin{array}{l}\text { Control } \\
\text { intervention }\end{array}$} & \multicolumn{2}{|c|}{$\begin{array}{l}\text { Mindfulness } \\
\text { intervention }\end{array}$} & \multirow[t]{2}{*}{$\begin{array}{l}\text { Statistics comparing demographics } \\
\text { between conditions }\end{array}$} \\
\hline & $M$ & $S D$ & $M$ & $S D$ & \\
\hline Age (years) & 26.68 & 7.32 & 27.88 & 9.24 & $t(111)=0.76, p=0.449, d=0.14$ \\
\hline RL & 5.86 & 6.10 & 7.48 & 8.07 & $t(111)=1.21, p=0.230, d=0.23$ \\
\hline Adherence & 6.40 & 0.73 & 5.27 & 1.01 & $t(79.29)=-6.22, p<0.001, d=1.28$ \\
\hline $\mathrm{TM}$ & 4.52 & 0.64 & 4.52 & 0.67 & $t(111)=0.08, p=0.936, d=0.02$ \\
\hline RS pre & 5.62 & 0.99 & 5.51 & 0.99 & $t(111)=-0.59, p=0.555, d=0.11$ \\
\hline RS post & 5.73 & 0.80 & 5.77 & 0.92 & $t(93)=0.23, p=0.818, d=0.05$ \\
\hline PA pre & 5.10 & 0.86 & 4.80 & 0.99 & $t(111)=-1.71, p=0.093, d=0.32$ \\
\hline \multirow[t]{2}{*}{ PA post } & 5.34 & 0.87 & 5.00 & 1.06 & $t(93)=-1.70, p=0.097, d=0.35$ \\
\hline & $N$ & $\%$ & $N$ & $\%$ & \\
\hline \multicolumn{6}{|l|}{ Gender } \\
\hline Female & 53 & 93 & 48 & 86 & \\
\hline Male & 4 & 7 & 8 & 14 & $x^{2}(1)=1.57, p=0.210$ \\
\hline \multicolumn{6}{|l|}{ Relationship status } \\
\hline Married & 13 & 23 & 12 & 21 & $x^{2}(1)=0.03, p=0.860$ \\
\hline Living together & 35 & 61 & 35 & 63 & $x^{2}(1)=0.01, p=0.904$ \\
\hline Children & 15 & 26 & 13 & 23 & $x^{2}(1)=0.24, p=0.623$ \\
\hline \multicolumn{6}{|l|}{ Level of education } \\
\hline Secondary & 6 & 11 & 10 & 18 & \\
\hline Basic vocational & 23 & 40 & 10 & 18 & \\
\hline \multirow{2}{*}{ Higher professional } & 28 & 49 & 36 & 64 & \\
\hline & & & & & $x^{2}(2)=7.11, p=0.029$ \\
\hline
\end{tabular}

$R L$ relationship length in years, $T M$ trait mindfulness, $R S$ pre relationship satisfaction at pretest, $P A$ pre partner acceptance at pretest. $\%$ refers to percentages within conditions. $n_{\text {control }}=57, n_{\text {mindfulness }}=56$

this automatic pilot, whereas participants in the control condition read that merely registering daily negative relationship experiences, if there were any, would be a way of disengaging the automatic pilot. On the first day, the psycho-educational material was displayed before participants could move on with the survey; on all other days, participants were free to read the material again. Note that the text did not specifically discuss the role of the automatic pilot in the context of romantic relationships. Whereas former studies have specifically adjusted mindfulness psycho-education and exercises for the couple context (e.g., Gambrel and Piercy 2015a, b,) in the present study, the material was offered without a specific context in order to explore whether beneficial effects of psychoeducation on the automatic pilot and/or practicing mindful awareness in general would spill over into the relationship context. The complete text can be found in the SM.

Providing this information in both conditions served several goals: First, it allowed us to distill the effects of daily meditation exercises, above and beyond the effects of psycho-education. Second, the information provided a framework for the mindfulness exercises, aimed at enhancing understanding of and motivation to do the exercises daily. Third, it provided a conceivable justification for the daily registering of negative relationship events for participants in the control condition, also with the aim of enhancing adherence. Finally, by offering this information to participants in both conditions, we kept potential demand effects as similar as possible across both groups, as all participants expected the intervention to increase awareness and reduce acting on automatic pilot.

Registering the Occurrence (or Absence of) Negative Relationship Experiences Each day, participants in both conditions filled in a survey in which they were asked whether or not a situation had occurred in their relationship that had caused negative emotions towards their partner ("Once in a while, everyone experiences less pleasant moments in their relationship. Different situations can evoke negative feelings. Today, has there been a situation that evoked negative emotions towards your partner?"). In the mindfulness condition, if the answer ("yes"/"no") to this question was "no," the survey automatically directed participants to the mindfulness exercise (explained in more detail below); for participants in the control condition, the survey ended here. If they answered "yes," in both conditions, an empty textbox appeared and participants were asked to type a short description of the situation. The textbox was followed by a few questions pertaining to the situation (including state mindfulness, rumination, and state acceptance). Due to the low average amount of negative 
incidences reported (on average 2 over the course of 2 weeks), the amount of data from these daily measures was too limited and will therefore not be discussed further. For participants in the control condition, the survey ended here. Participants in the mindfulness condition were now directed to the mindfulness exercise. To be clear, the registering of negative experiences (or their absence) was a daily activity in both conditions, which, for participants in the mindfulness condition, always preceded the mindfulness exercise. The complete questionnaire can be found in the supplementary materials (SM).

Mindfulness Exercises Participants in the mindfulness condition completed a mindfulness exercise on a daily basis, regardless of whether or not a negative incident had occurred in their relationship that day. Importantly, however, the occurrence (or absence) of negative experiences on a given day determined the kind of exercise participants were presented with: On days without negative experiences, participants practiced mindful awareness with the three building blocks of a "3-minute breathing space meditation" (as used in MBSR trainings): (1) becoming aware of presentmoment experiences (thoughts, emotions, bodily sensations), (2) focusing attention on breathing, and (3) expanding attention to the body as a whole, one's posture, and presence. The aim of this exercise is to practice becoming aware of present-moment experiences and observing them in a non-judgmental, accepting way.

On days they did report a negative relationship experience, participants practiced awareness "with a difficulty" (as often used in MBSR training): (1) focusing attention on breathing; (2) recalling and imagining the situation in which the negative experience occurred, and then becoming aware of any thoughts, emotions, and bodily sensations; and (3) expanding attention to the body as a whole, one's posture, and presence. The aim of this exercise is to practice applying mindful awareness to experiences in the face of difficult situations in the relationship.

Both exercises consisted of guided audio instructions that participants could play online. Lengths of the audio files were 8 and 10 min respectively. After the exercise, a short text reminded participants to transfer this state of awareness to any activity they were about to do during the day as to disengage the automatic pilot.

\section{Measures}

Relationship Satisfaction Relationship satisfaction was measured with five items of the Global Satisfaction subscale from the Investment Model Scale (Rusbult et al. 1998; e.g., "I feel satisfied with our relationship"). Respondents indicated their level of agreement on a 7-point Likert scale. In the present study, Cronbach's alpha was 0.85 at baseline and 0.86 at posttest. This subscale has been used on its own in previous research and has shown good psychometric properties (Ritter et al. 2010; Rusbult et al. 1998).

Partner Acceptance Acceptance of negative characteristics of the partner was measured with the Partner Acceptance Scale (PAS) (Kappen et al. 2018). Respondents rated the degree to which five statements applied to their own situation. The statements express acceptance of the partner and his/her flaws and consisted of positively ("I can accept the less pleasant characteristics of my partner.") as well as negatively ("I try to change the things which I do not like about my partner.") stated items. Respondents indicated their level of agreement on a 7-point Likert scale. The scale has shown good psychometric properties in pilot studies (Kappen et al. 2018). In the present study, Cronbach's alpha was rather low at baseline, 0.63 (all items contributed to reliability), and 0.75 at posttest.

Trait Mindfulness Trait mindfulness was assessed with the 24item version of the Five Facet Mindfulness Questionnaire Short Form (FFMQ-SF Dutch version; Bohlmeijer et al. 2011). The FFMQ covers five facets that have been identified as the main building blocks of trait mindfulness: observing, describing, acting with awareness, accepting without judgment, and non-reactivity Baer et al. (2006). Participants rated their agreement to 24 statements on a scale from 1 (never or almost never true) to 7 (very often or always true). In the present study, Cronbach's alpha for the full scale was 0.83 . In recent years, it has become a common practice to investigate the role of the five facets of the scale as predictors of outcomes separately (Khaddouma et al. 2015; Lenger et al. 2017). In the current project, we were interested in participants' average level of mindfulness, which can best be approximated by the full scale, rather than the separate facets. We therefore calculated participants' average score across all facets as an indicator of trait mindfulness, as has been done in earlier studies (Hertz et al. 2015; Jones et al. 2011; Kappen et al. 2018; Pepping et al. 2014).

Additional Measures The present study included a number of additional measures that are not relevant to the present research question and are therefore not further discussed in this manuscript. The complete survey and a list of additional measures can be found in the supplementary materials (SM).

Adherence to Task Instructions Participants reported how seriously they had completed the exercises of the study by answering the question "Indicate how seriously you have completed the exercises of this study." Response options ranged from 1 (not at all seriously) to 7 (very seriously). Task adherence was generally high (Tables 1 and 2). Participants were excluded when they scored $2 S D$ below the mean or lower on this measure $(n=5)$. Participants in the control condition indicated significantly higher adherence than participants in the 
Table 2 Means, standard deviations, and correlations for the entire analytic sample

\begin{tabular}{|c|c|c|c|c|c|c|c|c|c|}
\hline Variable & $M$ & $S D$ & 1 & 2 & 3 & 4 & 5 & 6 & 7 \\
\hline 1. TM & 4.52 & 0.65 & & & & & & & \\
\hline 2. RS pre & 5.57 & 0.99 & 0.12 & & & & & & \\
\hline 3. PA pre & 4.95 & 0.93 & $0.38 * *$ & $0.42 * *$ & & & & & \\
\hline 4. RS post & 5.75 & 0.86 & $0.26^{*}$ & $0.79 * *$ & $0.42 * *$ & & & & \\
\hline 5. PA post & 5.18 & 0.97 & $0.28 * *$ & $0.30 * *$ & $0.69 * *$ & $0.46 * *$ & & & \\
\hline 6. Adherence & 5.86 & 1.04 & 0.16 & 0.05 & 0.17 & 0.14 & $0.30 * *$ & & \\
\hline 7. Age & 27.27 & 8.31 & $0.27 * *$ & $-0.21^{*}$ & -0.01 & 0.00 & -0.02 & 0.06 & \\
\hline 8. RL & 6.66 & 7.16 & 0.11 & $-0.19 *$ & -0.03 & -0.04 & 0.04 & -0.05 & $0.68 * *$ \\
\hline
\end{tabular}

$T M$ trait mindfulness, $R S$ relationship satisfaction, $P A$ partner acceptance, pre scores at pretest, post scores at posttest, $R L$ relationship length in years; ${ }^{*} p<0.05 ; * * p<0.01 ; n=100-113$

mindfulness condition (Table 1). This can be explained by the greater daily task load in the mindfulness condition. Adherence was related to partner acceptance at posttest but did not correlate with trait mindfulness (Table 2). Adherence did not interact with condition to predict outcomes.

\section{Data Analyses}

For all measures, scores on negatively framed items were recoded and an average score of all items provided an overall index of the construct measured. All analyses were performed in the R statistical program (R Core Team 2018). Preliminary analyses include bivariate correlations between all study measures and $t$ tests examining mean-level differences between conditions. Intervention effects were tested using repeated measures ANOVAs, including time, condition, and the time $\times$ condition interaction as predictors of relationship satisfaction and partner acceptance. The analyses investigating trait mindfulness as a moderator were performed using the lavaan package (Rosseel 2012). This package was used to account for missing values on the post-intervention measures (13 participants did not complete measures at post-intervention) by using full-information maximum likelihood estimation. Two regression analyses were performed, one for each postintervention outcome measure (relationship satisfaction and partner acceptance). Each model included the baseline assessment of the outcome (either satisfaction or acceptance), condition (intervention and control), trait mindfulness, and the interaction between condition and trait mindfulness as predictors. Statistically significant interactions were followed up by calculating simple slopes at low (-1SD), average and high (+ $1 S D$ ) values of trait mindfulness and computing regions of significance using the Johnson-Neyman technique, which identifies the points on a continuous moderator at which the relationship between the dependent and independent variables is statistically significant (Hayes and Matthes 2009; Johnson and Fay 1950). These post hoc analyses were performed using the jtools package in R (Long 2018).
Data Availability Supplementary materials and data without personal information can be found on the Open Science Framework: (https://osf.io/9gfxv/?view_only= 0a5f81c8188a47e0808fa187903d0018).

\section{Results}

\section{Relationship Satisfaction}

Preliminary Analyses Scores on relationship satisfaction did not differ between conditions at baseline or posttest (Table 1). Correlations between trait mindfulness and relationship satisfaction at baseline were not statistically significant and thus did not confirm earlier findings (Table 2). Trait mindfulness was positively correlated with relationship satisfaction at posttest. Age and length of the relationship were positively related to relationship satisfaction at baseline (Table 2).

Intervention Effects Repeated measures ANOVA showed no significant time $\times$ condition interaction, $F(1,93)=1.81$, $\eta_{\text {partial }}^{2}=0.02, p=0.18$, indicating that participants did not benefit significantly more from the mindfulness intervention than from the control intervention. However, a significant main effect of time indicated that relationship satisfaction increased from pre- to post-intervention across conditions, $F(1,93)=5.94, \eta_{\text {partial }}^{2}=0.06, p=0.02$. Condition was not a significant predictor of relationship satisfaction, $F(1,93)=$ $0.06, \eta_{\text {partial }}^{2}=0.001, p=0.81$.

Moderation by Trait Mindfulness The regression model including baseline levels of satisfaction, condition, trait mindfulness, and the interaction between condition and trait mindfulness as predictors explained $67 \%$ of the variance in relationship satisfaction at post-intervention. The results can be found in Table 3 . The interaction between condition and trait mindfulness did emerge as a significant predictor of postintervention satisfaction. This indicates that changes in 
Table 3 Results of multiple regression analyses, testing the moderating effect of trait mindfulness

\begin{tabular}{|c|c|c|c|c|c|c|}
\hline Predictor & $B$ & SE $B$ & $\beta$ & $95 \% \mathrm{CI}$ & $t$ & $p$ \\
\hline \multicolumn{7}{|l|}{ RS posttest } \\
\hline RS pretest & 0.68 & 0.05 & 0.79 & $0.58-0.78$ & 13.03 & $<0.001$ \\
\hline Condition & -0.12 & 0.10 & -0.07 & $-0.32-0.07$ & -1.24 & 0.217 \\
\hline $\mathrm{TM}$ & -0.29 & 0.23 & -0.23 & $-0.74-0.16$ & -1.27 & 0.208 \\
\hline Condition $\times \mathrm{TM}$ & 0.34 & 0.15 & 0.40 & $0.04-0.63$ & 2.29 & 0.024 \\
\hline \multicolumn{7}{|l|}{ PA posttest } \\
\hline PA pretest & 0.71 & 0.08 & 0.69 & $0.55-0.87$ & 8.65 & $<0.001$ \\
\hline Condition & 0.08 & 0.14 & 0.04 & $-0.20-0.36$ & 0.56 & 0.576 \\
\hline $\mathrm{TM}$ & -0.44 & 0.33 & -0.30 & $-1.09-0.22$ & -1.33 & 0.186 \\
\hline Condition $\times \mathrm{TM}$ & 0.32 & 0.21 & 0.33 & $-0.09-0.74$ & 1.54 & 0.128 \\
\hline
\end{tabular}

relationship satisfaction did not differ as a function of intervention condition, but the effect of condition on changes in relationship satisfaction differed as a function of trait mindfulness.

Conditional effects showed that there was a beneficial effect of the mindfulness intervention as compared to the control intervention for participants who entered the study with relatively low levels of trait mindfulness $(-1 S D$ below the mean, $B=-0.34, S E B=0.14, p=0.02)$, whereas for average $(B=-$ $0.13, S E B=0.10, p=0.24)$ and high (+ $1 S D$ above the mean, $B=0.11, S E B=0.14, p=0.43$ ) levels of trait mindfulness, there was no effect of condition on post-intervention relationship satisfaction (see Fig. 1 for simple slopes). JohnsonNeyman analyses of regions of significance revealed that the mindfulness intervention, as compared to the control group, had a positive effect on post-intervention relationship satisfaction from trait mindfulness levels of 4.31 and below. Thus, for a substantial proportion of our sample (42\% of participants had trait mindfulness scores lower than 4.31), the mindfulness (versus control) intervention led to higher levels of postintervention relationship satisfaction. The condition $\times$ trait mindfulness interaction remained a significant predictor of posttest relationship satisfaction when controlling for marital status, cohabitation, gender, and relationship length.

\section{Partner Acceptance}

Preliminary Analyses Scores on partner acceptance did not differ significantly between conditions at baseline and posttest (Table 1). Trait mindfulness positively correlated with levels of partner acceptance at baseline as well as at posttest (Table 2).

Intervention Effects Repeated measures ANOVA showed no significant time $\times$ condition interaction, $F(1,93)=0.03$, $\eta_{\text {partial }}^{2}=0.00, p=0.88$, indicating that participants did not benefit significantly more from the mindfulness intervention than from the control intervention. However, a significant main effect of time indicated that partner acceptance increased from pre- to post-intervention across conditions, $F(1,93)=$ $4.63, \eta_{\text {partial }}^{2}=0.05, p=0.03$. Condition was not a significant predictor of partner acceptance, $F(1,93)=3.34, \eta_{\text {partial }}^{2}=$ $0.04, p=0.07$.

Moderation by Trait Mindfulness A regression model including baseline levels of acceptance, condition, trait mindfulness, and the interaction between condition and trait mindfulness as predictors predicted $50 \%$ of the variance in partner acceptance at post-intervention. Pre-intervention levels of acceptance were the only significant predictor of acceptance at post-intervention. Importantly, the interaction term between condition and trait mindfulness was not statistically significant, suggesting that effects of condition on partner acceptance did not differ for different levels of trait mindfulness. Controlling for marital status, cohabitation, gender, relationship length, and relationship satisfaction at pretest did not change the outcomes.

\section{Discussion}

Can a 12-day online-based mindfulness intervention promote romantic relationship satisfaction? The present findings provide some mixed support. Indeed, overall, we found an increase in relationship satisfaction from pre- to postintervention in the mindfulness intervention group, though this increase did not differ significantly from a control intervention group that was given the same psycho-education and completed the same daily measures but did not practice mindfulness. However, practicing mindfulness did make a difference for those participants who scored relatively low on trait mindfulness at the start of the training. Specifically, for participants with low levels of trait mindfulness, the mindfulness intervention promoted relationship satisfaction, whereas the control intervention did not. Thus, although in the mindfulness intervention participants of all levels of mindfulness 


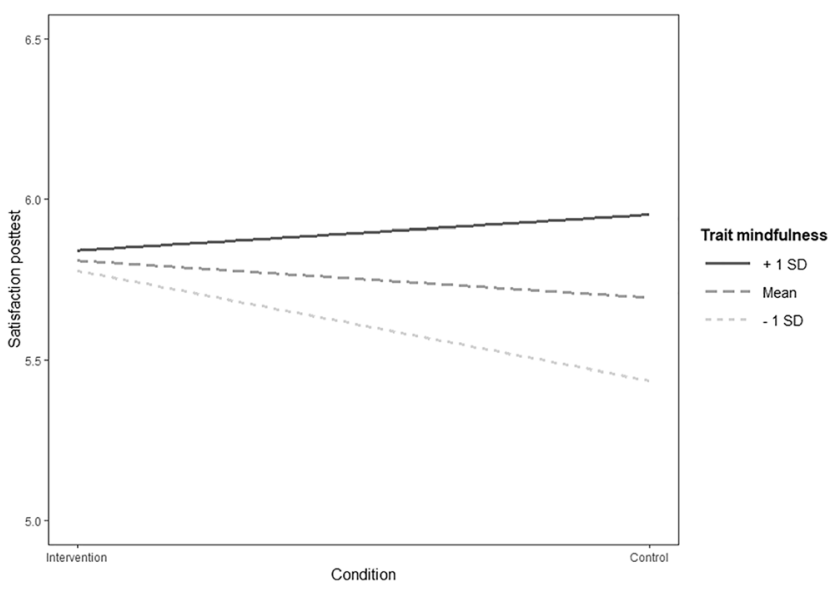

Fig. 1 Intervention effects at three levels of trait mindfulness (moderator)

improved in relationship satisfaction, this increase was only significantly different from the effects of the control intervention for people low in trait mindfulness.

Although increases in partner acceptance were associated with increases in relationship satisfaction, we did not find support for the prediction that partner acceptance could account for increases in relationship satisfaction as a result of the mindfulness intervention. Overall, participants in both conditions slightly increased in partner acceptance. Merely reflecting on and writing about experiences in the relationship might have improved relationship well-being (e.g., Baikie and Wilhelm 2005; Slatcher and Pennebaker 2006). Also, by daily reporting on negative relationship experiences, participants might have come to appreciate the positive aspects of their relationship even more. For instance, participants commented: "I realized that I only have few irritations about my partner" and "In retrospect, I'd say I now appreciate my partner even more!" Currently, we are aware of only one study that investigated and found a causal link between mindfulness and partner acceptance, employing an 8-week relationship-tailored mindfulness training (Carson et al. 2004). More research is needed to conclude whether lower dose practice of mindfulness also can foster partner acceptance, above and beyond the effects of increased reflection on the relationship. Whether or not mindfulness interventions can increase partner acceptance in romantic partners, it is important to note that fostering partner acceptance may be beneficial for couples only within certain boundaries (Kappen et al. 2018). Individuals practicing acceptance must be careful to distinguish relatively innocent partner behaviors (i.e., partner imperfections) from abusive or otherwise damaging behaviors. In the latter case, acceptance (or rather resignation) may act as a permit for the abusive partner to continue behaving this way and non-acceptance may be required to move the relationship in a healthier direction (Baker et al. 2014; Luchies et al. 2010). Researchers have proposed that mindfulness may help individuals recognize otherwise implicitly held beliefs that keep them in an abusive relationship (Kappen et al. 2018; Karremans et al. 2017). Whether mindfulness indeed enables people to make a distinction between healthy and unhealthy acceptance is an important theoretical question future research should address.

What made the mindfulness intervention effective for participants low in trait mindfulness? Previous research has linked mindfulness interventions as well as trait mindfulness with processes like improved recognition of and communication about emotions, better executive functioning, and better emotion regulation (Creswell et al. 2007; Goldin and Gross 2010; Heeren et al. 2009; Teper and Inzlicht 2013; Wachs and Cordova 2007). In the context of romantic relationships, correlational studies point to the potential of mindfulness skills to buffer the impact of automatic negative impulses on relationship-destructive behavior (Dixon and Overall 2016; Iida and Shapiro 2017; Saavedra et al. 2010). The present study is one of the first to causally investigate the association between practicing mindfulness and romantic relationship quality, and future research should further explore the exact mechanisms through which this may occur.

An interesting question is why the low-dose online mindfulness intervention was particularly valuable for people with low levels of trait mindfulness. As we reasoned in the introduction, one plausible explanation might be that, in order to benefit from a short online intervention, people who are naturally not very mindful might need to practice mindfulness with formal exercises. Moreover, perhaps people who were already high in trait mindfulness approached the exercises in the control condition (writing about negative events in the relationship) already in a relatively mindful manner, which may explain the fact that people high in trait mindfulness profited as much from the control condition as from the mindfulness condition. Also, for this group, psycho-education may have acted as a reminder to "use" their inherent mindfulness skills in everyday life.

Interestingly, previous research found that participants with low baseline levels of trait mindfulness had lower treatment outcomes than participants with higher baseline levels of trait mindfulness (Shapiro et al. 2011), possibly because higher levels of trait mindfulness facilitate adherence to the program (Forbes et al. 2018). In contrast to these findings, in the present study, trait mindfulness was not related to (self-reported) adherence and participants with low levels of trait mindfulness particularly benefited from the mindfulness intervention. We suggest that the relatively low investment that was required for the present, online-based intervention might have facilitated adherence for participants who would otherwise struggle with completing a more intense mindfulness training program. In other words, participants with low levels of trait mindfulness might adhere better to low-dose or less intensive treatments than to more intensive programs. However, given the lack of studies structurally investigating this question, at this point, we can only speculate about whether this is indeed the case. 
In order to get a grip on the feasibility of online mindfulness programs in general and on the role of trait mindfulness and other individual factors as predictors of treatment outcomes in particular, much more work needs to be done.

If future studies confirm that individuals with low levels of trait mindfulness respond better to online trainings than to more intense programs, practitioners might consider to routinely offer an additional, low-dose online version of their training to participants, ideally before starting the more intense face-to-face program. In this way, individuals with low levels of trait mindfulness can become familiar with the practice more gradually and might be better able to adhere to a more intense program later on. This might increase the likelihood that individuals optimally benefit from the available options or a combination thereof and might prevent high dropout rates.

Asking participants to practice decentering on negative emotions towards a partner might raise concerns. Whereas a certain level of negative experiences is necessary to practice a decentering attitude towards these experiences, there is a danger that decentering is used on the "wrong kind" of experiences, for example, to endure abusive partner behaviors. Though this concern also holds for regular mindfulness interventions, it might be a particular danger for online trainings due to a lack of professional supervision. In the absence of face-to-face contact with a teacher and other trainees, online mindfulness trainings may therefore include support features (online community, teacher contact via chat or phone), where trainees have the opportunity to ask questions and can get support. A meta-analysis showed that online self-help interventions for depressive symptoms were more effective when minimal therapist guidance was provided (Gellatly et al. 2007) and it seems valuable to investigate this possibility in the case of online mindfulness interventions. Note that the need for support might depend on the amount of participants' knowledge about and experience with mindfulness meditation.

The present study investigated the effects of mindfulness exercises in a generally healthy, non-distressed sample. According to the stress-buffering account of mindfulness (Creswell and Lindsay 2014), effects of mindfulness exercises might be more prominent in high-stress samples, as there simply would be more stress effects to be buffered. To examine this prediction, future research could, for example, pre-select couples based on higher levels of relationship distress. At the same time, some scholars have argued that a complete theory of mindfulness should also include the promotion of positive mental states (Garland et al. 2015). In the spirit of the field's movement from a problem-focused to a more health-focused science of relationships (Fincham and Beach 2010), future studies may therefore also include measures of relationship flourishing and more specific positive relationship processes (e.g., general positive affect, affection, appreciation, shared fun and joy, and capitalizing on positive events), to capture the potential effects of mindfulness interventions on romantic relationships more fully. In a similar vein, instead of focusing on accepting negative aspects of a partner, as was done in the present study, future mindfulness interventions might target people's awareness of these positive processes and positive partner characteristics to boost relationship satisfaction.

The present findings showed that a control condition that provided psycho-education on the automatic pilot could already lead to increases in relationship satisfaction and partner acceptance. Although of course various factors may have contributed to this effect (e.g., increased awareness of the relationship), this finding underscores the importance of using active instead of waiting list control groups, as recently argued (Van Dam et al. 2017). Mindfulness researchers in particular might find value in exploring the effects of psycho-education, given that it is a main ingredient of most mindfulness-based interventions and exercises. Study designs controlling for awareness for the relationship and a psycho-education separately may further distill the effects of psycho-education.

\section{Strengths and Limitations}

The present study is the first to examine the effects of a low-dose online mindfulness intervention on romantic relationship quality. Moreover, and in correspondence with a recent call (Van Dam et al. 2017), we used an (albeit minimally) active control group instead of a waiting list control group to examine the effects of mindfulness exercises. The study design controlled for possible demand effects as well as effects due to psycho-education that is typically given alongside mindfulness exercises. Also, the study provides further insight into who might benefit most from a lowdose mindfulness intervention, focusing on the role of trait mindfulness. In the current era, in which online mindfulness apps and programs are becoming increasingly popular, the present findings support the general notion that such interventions not only may affect personal wellbeing (e.g., Cavanagh et al. 2013; Spijkerman et al. 2016), but can even affect how people perceive the quality of their romantic relationship.

The present study also comes with limitations. First, outcomes, as well as adherence to the program, were assessed using online self-report measures, which might be particularly prone to response biases and dishonest responding. To reduce these risks, however, we checked participants' initial commitment to the study with a phone call and the low dropout rate indicates that this might have been a successful strategy to enhance data quality. In addition, future research should include more objective measures of adherence (e.g., log the amount of time participants spend on the exercise) as well as measures that assess behavioral outcomes in the relationship context (e.g., observation of how partners act during conflict). Second, the current findings can be seen as a proof of principle; however, we do not know yet how long the effects last. 
Third, the pre- and post-measures of relationship satisfaction and partner acceptance may have failed to capture more subtle changes in relationship functioning. (Notably, one participant complained that the questionnaires did not capture the relationship changes he or she had noticed). For example, a recent study found that increases in daily levels of mindful attention were related to daily levels of social connection (Adair et al. 2017b). Thus, future studies should include measures that cover specific relationship processes and indicators that might be more malleable than general relationship satisfaction, like conflict handling, connectedness, content and quality of communication, or responsiveness to a partner. Fourth, and related to this issue, we only investigated the effect of the mindfulness intervention on the trainee's perception of relationship satisfaction. An important next step would be to explore whether the training of mindfulness affects outcomes in the partner (i.e., partner effects; Kashy and Kenny 2000). Finally, an important limitation of the present research is that the sample consisted mainly of women (92\%), restricting the generalizability of these findings.

Research on the effects of mindfulness in romantic relationships is growing rapidly, but given the fact that most research findings are based on trait levels of mindfulness, an important open question is whether the practice and training of mindfulness can affect the functioning of romantic relationships. The present study revealed that a short, online, selfadministered mindfulness-based intervention is more effective in improving relationship satisfaction than a minimally active control group, for a subset of participants who scored low on a trait measure of mindfulness. While these findings are encouraging, future research should further explore how mindfulness training can affect relationship satisfaction, and it should focus on a wider variety of relationship outcomes. In this way, we can get a more complete understanding of the breadth and boundaries of the effects of mindfulness in the context of romantic relationships. Our sense is that this endeavor has only just begun.

Author Contributions GK designed and executed the studies, assisted with data analyses, and wrote the paper. JK co-developed the study design, consulted on the execution of the studies, and assisted in writing the paper. WB analyzed the data and wrote parts of the results section.

\section{Compliance with Ethical Standards}

Conflict of Interest The authors declare that they have no conflict of interest.

Ethical Standards All procedures performed in this study involving human participants were in accordance with the ethical standards of the Ethical Committee of the Faculty of Social Sciences of Radboud University (reference number: ECSW2015-0903-304) and with the 1964 Helsinki declaration and its later amendments or comparable ethical standards. Ethical consent was obtained from all participants before participation.
Open Access This article is distributed under the terms of the Creative Commons Attribution 4.0 International License (http:// creativecommons.org/licenses/by/4.0/), which permits unrestricted use, distribution, and reproduction in any medium, provided you give appropriate credit to the original author(s) and the source, provide a link to the Creative Commons license, and indicate if changes were made.

\section{References}

Adair, K. C., Boulton, A. J., \& Algoe, S. B. (2017a). The effect of mindfulness on relationship satisfaction via perceived responsiveness: Findings from a dyadic study of heterosexual romantic partners. Mindfulness, 9(2), 597-609. https://doi.org/10.1007/s12671-0170801-3.

Adair, K. C., Fredrickson, B. L., Castro-Schilo, L., \& Kim, S. (2017b). Present with you: Does cultivated mindfulness predict greater social connection through gains in decentering and reductions in negative emotions? Mindfulness, 9(3), 737-749. https://doi.org/10.1007/ s12671-017-0811-1.

Alberts, H. J. E. M. (2017). Studying mindfulness with different methods. In J. C. Karremans \& E. K. Papies (Eds.), Mindfulness in social psychology (pp. 15-29). London: Routledge.

Arch, J. J., \& Craske, M. G. (2006). Mechanisms of mindfulness: emotion regulation following a focused breathing induction. Behavior Research and Therapy, 44(12), 1849-1858. https://doi.org/10. 1016/j.brat.2005.12.007.

Baer, R. A., Smith, G. T., Hopkins, J., Krietemeyer, J., \& Toney, L. (2006). Using self-report assessment methods to explore facets of mindfulness. Assessment, 13(1), 27-45. https://doi.org/10.1177/ 1073191105283504.

Baikie, K. A., \& Wilhelm, K. (2005). Emotional and physical health benefits of expressive writing. Advances in Psychiatric Treatment, 11(5), 338-346. https://doi.org/10.1192/apt.11.5.338.

Baker, L. R., McNulty, J. K., \& Overall, N. C. (2014). When negative emotions benefit close relationships. In W. G. Parrott (Ed.), The positive side of negative emotions (pp. 101-125). New York: Guilford Press.

Barnes, S., Brown, K. W., Krusemark, E., Campbell, W. K., \& Rogge, R. D. (2007). The role of mindfulness in romantic relationship satisfaction and responses to relationship stress. Journal of Marital Family Therapy, 33(4), 482-500. https://doi.org/10.1111/j.1752-0606.2007. 00033.x.

Bishop, S. R., Lau, M., Shapiro, S., Carlson, L., Anderson, N. D., Carmody, J., et al. (2004). Mindfulness: a proposed operational definition. Clinical Psychology: Science and Practice, 11(3), 230-241. https://doi.org/10.1093/clipsy/bph077.

Bohlmeijer, E., ten Klooster, P. M., Fledderus, M., Veehof, M., \& Baer, R. (2011). Psychometric properties of the Five Facet Mindfulness Questionnaire in depressed adults and development of a short form. Assessment, 18(3), 308-320. https://doi.org/10.1177/ 1073191111408231 .

Bravo, A. J., Boothe, L. G., \& Pearson, M. R. (2016). Getting personal with mindfulness: A latent profile analysis of mindfulness and psychological outcomes. Mindfulness, 7(2), 420-432. https://doi.org/ 10.1007/s12671-015-0459-7.

Brown, K. W., \& Ryan, R. M. (2003). The benefits of being present: Mindfulness and its role in psychological well-being. Journal of Personality and Social Psychology, 84(4), 822-848. https://doi. org/10.1037/0022-3514.84.4.822.

Caldwell, J. G., \& Shaver, P. R. (2013). Mediators of the link between adult attachment and mindfulness. Interpersona, 7(2), 299-310. https://doi.org/10.5964/ijpr.v7i2.133.

Carmody, J., Reed, G., Kristeller, J., \& Merriam, P. (2008). Mindfulness, spirituality, and health-related symptoms. Journal of Psychosomatic 
Research, 64(4), 393-403. https://doi.org/10.1016/J. JPSYCHORES.2007.06.015.

Carson, J. W., Carson, K. M., Gil, K. M., \& Baucom, D. H. (2004). Mindfulness-based relationship enhancement. Behavior Therapy, $35,471-494$.

Cavanagh, K., Strauss, C., Cicconi, F., Griffiths, N., Wyper, A., \& Jones, F. (2013). A randomised controlled trial of a brief online mindfulness-based intervention. Behavior Research and Therapy, 51(9), 573-578. https://doi.org/10.1016/j.brat.2013.06.003.

Chiesa, A., \& Serretti, A. (2009). Mindfulness-based stress reduction for stress management in healthy people: a review and meta-analysis. Journal of Alternative and Complementary Medicine, 15(5), 593600. https://doi.org/10.1089/acm.2008.0495.

Chiesa, A., Calati, R., \& Serretti, A. (2011). Does mindfulness training improve cognitive abilities? A systematic review of neuropsychological findings. Clinical Psychology Review, 31(3), 449-464. https://doi.org/10.1016/j.cpr.2010.11.003.

Ciesla, J. A., Reilly, L. C., Dickson, K. S., Emanuel, A. S., \& Updegraff, J. A. (2012). Dispositional mindfulness moderates the effects of stress among adolescents: rumination as a mediator. Journal of Clinical Child and Adolescent Psychology, 41(6), 760-770. https:// doi.org/10.1080/15374416.2012.698724.

Creswell, J. D., \& Lindsay, E. K. (2014). How does mindfulness training affect health? A mindfulness stress buffering account. Current Directions in Psychological Science, 23(6), 401-407. https://doi. org/10.1177/0963721414547415.

Creswell, J. D., Way, B. M., Eisenberger, N. I., \& Lieberman, M. D. (2007). Neural correlates of dispositional mindfulness during affect labeling. Psychosomatic Medicine, 69(6), 560-565. https://doi.org/ 10.1097/PSY.0b013e3180f6171f.

Dixon, H. C., \& Overall, N. C. (2016). Regulating fears of rejection: Dispositional mindfulness attenuates the links between daily conflict, rejection fears, and destructive relationship behaviors. Journal of Social and Personal Relationships, 35(2), 159-179. https://doi. org/10.1177/0265407516678486.

Economides, M., Martman, J., Bell, M. J., \& Sanderson, B. (2018). Improvements in stress, affect, and irritability following brief use of a mindfulness-based smartphone app: A randomized controlled trial. Mindfulness, 9(5), 1584-1593. https://doi.org/10.1007/ s12671-018-0905-4.

Farias, M., \& Wikholm, C. (2016). Has the science of mindfulness lost its mind? BJPsych Bulletin, 40(6), 329-332. https://doi.org/10.1192/ pb.bp.116.053686.

Fincham, F. D., \& Beach, S. R. H. (2010). Of Memes and marriage: Toward a positive relationship science. Journal of Family Theory \& Review, 2(1), 4-24. https://doi.org/10.1111/j.1756-2589.2010. 00033.x.

Forbes, L., Gutierrez, D., \& Johnson, S. K. (2018). Investigating adherence to an online introductory mindfulness program. Mindfulness, 9(1), 271-282. https://doi.org/10.1007/s12671-017-0772-4.

Gambrel, L. E., \& Piercy, F. P. (2015a). Mindfulness-based relationship education for couples expecting their first child-part 1: A randomized mixed-methods program evaluation. Journal of Marital and Family Therapy, 41(1), 5-24. https://doi.org/10.1111/jmft.12066.

Gambrel, L. E., \& Piercy, F. P. (2015b). Mindfulness-based relationship education for couples expecting their first child-part 2: Phenomenological findings. Journal of Marital and Family Therapy, 41(1), 25-41. https://doi.org/10.1111/jmft.12065.

Garland, E. L., Farb, N. A., Goldin, R., P., \& Fredrickson, B. L. (2015). Mindfulness broadens awareness and builds eudaimonic meaning: A process model of mindful positive emotion regulation. Psychological Inquiry, 26(4), 293-314. https://doi.org/10.1080/ 1047840X.2015.1064294.

Gellatly, J., Bower, P., Hennessy, S., Richards, D., Gilbody, S., \& Lovell, K. (2007). What makes self-help interventions effective in the management of depressive symptoms? Meta-analysis and meta- regression. Psychological Medicine, 37, 1217-1228. https://doi. org/10.1017/S0033291707000062.

Glück, T. M., \& Maercker, A. (2011). A randomized controlled pilot study of a brief web-based mindfulness training. BMC Psychiatry, 11(1), 175. https://doi.org/10.1186/1471-244X-11-175.

Goldin, P. R., \& Gross, J. J. (2010). Effects of mindfulness-based stress reduction (MBSR) on emotion regulation in social anxiety disorder. Emotion, 10(1), 83-91. https://doi.org/10.1037/a0018441.

Goodall, K., Trejnowska, A., \& Darling, S. (2012). The relationship between dispositional mindfulness, attachment security and emotion regulation. Personality and Individual Differences, 52, 622-626. https://doi.org/10.1016/j.paid.2011.12.008.

Grepmair, L., Mitterlehner, F., Loew, T., Bachler, E., Rother, W., \& Nickel, M. (2007). Promoting mindfulness in psychotherapists in training influences the treatment results of their patients: A randomized, double-blind, controlled study. Psychotherapy and Psychosomatics, 76, 332-338. https://doi.org/10.1159/000107560.

Grossman, P., Niemann, L., Schmidt, S., \& Walach, H. (2004). Mindfulness-based stress reduction and health benefits A meta-analysis. Journal of Psychosomatic Research, 57(1), 35-43. https://doi. org/10.1016/S0022-3999(03)00573-7.

Hayes, S. C. (2004). Acceptance and commitment therapy, relational frame theory, and the third wave of behavioral and cognitive therapies. Behavior Therapy, 35(4), 639-665. https://doi.org/10.1016/ S0005-7894(04)80013-3.

Hayes, A. F., \& Matthes, J. (2009). Computational procedures for probing interactions in OLS and logistic regression: SPSS and SAS implementations. Behavior Research Methods, 41(3), 924-936. https://doi.org/10.3758/BRM.41.3.924.

Heeren, A., Van Broeck, N., \& Philippot, P. (2009). The effects of mindfulness on executive processes and autobiographical memory specificity. Behaviour Research and Therapy, 47(5), 403-409. https:// doi.org/10.1016/j.brat.2009.01.017.

Heppner, W. L., \& Shirk, S. D. (2018). Mindful moments: A review of brief, low-intensity mindfulness meditation and induced mindful states. Social and Personality Psychology Compass, 12(12), e12424. https://doi.org/10.1111/spc3.12424.

Hertz, R. M., Laurent, H. K., \& Laurent, S. M. (2015). Attachment Mediates Effects of Trait Mindfulness on Stress Responses to Conflict. Mindfulness, 6(3), 483-489. https://doi.org/10.1007/ s12671-014-0281-7.

Howells, A., Ivtzan, I., \& Eiroa-Orosa, F. J. (2016). Putting the 'app' in happiness: A randomised controlled trial of a smartphone-based mindfulness intervention to enhance wellbeing. Journal of Happiness Studies, 17(1), 163-185. https://doi.org/10.1007/ s10902-014-9589-1.

Hülsheger, U. R., Alberts, H. J. E. M., Feinholdt, A., \& Lang, J. W. B. (2013). Benefits of mindfulness at work: the role of mindfulness in emotion regulation, emotional exhaustion, and job satisfaction. Journal of Applied Psychology, 98(2), 310-325. https://doi.org/10. 1037/a0031313.

Hülsheger, U. R., Feinholdt, A., \& Nübold, A. (2015). A low-dose mindfulness intervention and recovery from work: Effects on psychological detachment, sleep quality, and sleep duration. Journal of Occupational and Organizational Psychology, 88(3), 464-489. https://doi.org/10.1111/joop.12115.

Iida, M., \& Shapiro, A. F. (2017). The role of mindfulness in daily relationship process: Examining daily conflicts and relationship mood. Mindfulness, 8(6), 1559-1568. https://doi.org/10.1007/s12671-0170727-9.

Jacobson, N. S., Christensen, A., Prince, S. E., Cordova, J., \& Eldridge, K. (2000). Integrative behavioral couple therapy: An acceptancebased, promising new treatment for couple discord. Journal of Consulting and Clinical Psychology, 68(2), 351-355. https://doi. org/10.1037//0022-006X.68.2.351. 
Johnson, P. O., \& Fay, L. C. (1950). The Johnson-Neyman technique, its theory and application. Psychometrika, 15(4), 349-367. https://doi. org/10.1007/BF02288864.

Jones, K. C., Welton, S. R., Oliver, T. C., \& Thoburn, J. W. (2011). Mindfulness, spousal attachment, and marital satisfaction: A mediated model. The Family Journal, 19(4), 357-361. https://doi.org/10. $1177 / 1066480711417234$

Kabat-Zinn, J. (1982). An outpatient program in behavioral medicine for chronic pain patients based on the practice of mindfulness meditation: Theoretical considerations and preliminary results. General Hospital Psychiatry, 4(1), 33-47. https://doi.org/10.1016/01638343(82)90026-3.

Kabat-Zinn, J. (1990). Full catastrophe living: Using the wisdom of your body and mind to face stress, pain, and illness. New York: Delta.

Kappen, G., Karremans, J. C., Burk, W. J., \& Buyukcan-Tetik, A. (2018). On the association between mindfulness and romantic relationship satisfaction: The role of partner acceptance. Mindfulness, 9(5), 1543-1556. https://doi.org/10.1007/s12671-018-0902-7.

Karremans, J. C., Schellekens, M. P. J., \& Kappen, G. (2017). Bridging the sciences of mindfulness and romantic relationships: A theoretical model and research agenda. Personality and Social Psychology Review, 21(1), 29-49. https://doi.org/10.1177/1088868315615450.

Karremans, J. C., van Schie, H. T., van Dongen, I., Kappen, G., Mori, G., van As, S., ten Bokkel, I. M., \& van der Wal, R. C. (2019). Is Mindfulness Associated With Interpersonal Forgiveness?. Emotion. Advance online publication. https://doi.org/10.1037/ emo0000552.

Kashy, D. A., \& Kenny, D. A. (2000). The analysis of data from dyads and groups. In H. T. Reis \& C. M. Judd (Eds.), Handbook of research methods in social and personality psychology (pp. 451-477f). Cambridge: Cambridge University Press.

Keng, S.-L., Smoski, M. J., \& Robins, C. J. (2011). Effects of mindfulness on psychological health: A review of empirical studies. Clinical Psychology Review, 31(6), 1041-1056. https://doi.org/10.1016/j. cpr.2011.04.006.

Khaddouma, A., Gordon, K. C., \& Bolden, J. (2015). Zen and the art of sex: examining associations among mindfulness, sexual satisfaction, and relationship satisfaction in dating relationships. Sexual and Relationship Therapy, 30(2), 268-285. https://doi.org/10.1080/ 14681994.2014.992408.

Khaddouma, A., Coop Gordon, K., \& Strand, E. B. (2017). Mindful mates: A pilot study of the relational effects of mindfulness-based stress reduction on participants and their partners. Family Process, 56(3), 636-651. https://doi.org/10.1111/famp.12226.

Kimmes, J. G., Durtschi, J. A., \& Fincham, F. D. (2017). Perception in romantic relationships: a latent profile analysis of trait mindfulness in relation to attachment and attributions. Mindfulness, 8(5), 13281338. https://doi.org/10.1007/s12671-017-0708-z.

Koole, S. L., Govorun, O., Cheng, C. M., \& Gallucci, M. (2009). Pulling yourself together: Meditation promotes congruence between implicit and explicit self-esteem. Journal of Experimental Social Psychology, 45(6), 1220-1226. https://doi.org/10.1016/j.jesp.2009. 05.018 .

Lebois, L. A. M., Papies, E. K., Gopinath, K., Cabanban, R., Quigley, K. S., Krishnamurthy, V., et al. (2015). A shift in perspective: Decentering through mindful attention to imagined stressful events. Neuropsycholgia, 75, 505-524. https://doi.org/10.1016/j. neuropsychologia.2015.05.030.

Lenger, K. A., Gordon, C. L., \& Nguyen, S. P. (2017). Intra-individual and cross-partner associations between the five facets of mindfulness and relationship satisfaction. Mindfulness, 8(1), 171-180. https://doi.org/10.1007/s12671-016-0590-0.

Lim, D., Condon, P., \& De Steno, D. (2015). Mindfulness and compassion: An examination of mechanism and scalability. PLOS ONE, 10(2), e0118221. https://doi.org/10.1371/journal.pone.0118221.
Long, J. A. (2018). jtools: Analysis and presentation of social scientific data. Version 1.1.1. Retrieved from https://cran.r-project.org/ package $=$ jtools

Luchies, L. B., Finkel, E. J., McNulty, J. K., \& Kumashiro, M. (2010). The doormat effect: when forgiving erodes self-respect and selfconcept clarity. Journal of Personality and Social Psychology, 98(5), 734-749. https://doi.org/10.1037/a0017838.

Mcgill, J., Adler-Baeder, F., \& Rodriguez, P. (2016). Mindfully in love: a meta-analysis of the association between mindfulness and relationship satisfaction. Journal of Human Sciences and Extension, 4(1), 89-101.

Montes-Maroto, G., Rodríguez-Muñoz, A., Antino, M., \& Gil, F. (2017). Mindfulness beyond the individual: Spillover and crossover effects in working couples. Mindfulness, 9(4), 1258-1267. https://doi.org/ 10.1007/s12671-017-0868-x.

Pepping, C. A., O'Donovan, A., \& Davis, P. J. (2014). The differential relationship between mindfulness and attachment in experienced and inexperienced meditators. Mindfulness, 5(4), 392-399. https:// doi.org/10.1007/s12671-012-0193-3.

R Core Team. (2018). R: A language and environment for statistical computing. Vienna: R Foundation for Statistical Computing Retrieved from http://www.R-project.org/.

Ritter, S. M., Karremans, J. C., \& van Schie, H. T. (2010). The role of selfregulation in derogating attractive alternatives. Journal of Experimental Social Psychology, 46(4), 631-637. https://doi.org/ 10.1016/J.JESP.2010.02.010.

Rosseel, Y. (2012). Lavaan: an R package for structural equation modeling. Journal of Statistical Software, 48(2), 1-36.

Rusbult, C. E., Martz, J. M., \& Agnew, C. R. (1998). The Investment Model Scale: Measuring commitment level, satisfaction level, quality of alternatives, and investment size. Personal Relationships, 5(4), 357-391. https://doi.org/10.1111/j.1475-6811.1998.tb00177.x.

Ryan, A., Safran, J. D., Doran, J. M., \& Muran, J. C. (2012). Therapist mindfulness, alliance and treatment outcome. Psychotherapy Research, 22(3), 289-297. https://doi.org/10.1080/10503307.2011. 650653.

Saavedra, M. C., Chapman, K. E., \& Rogge, R. D. (2010). Clarifying links between attachment and relationship quality: Hostile conflict and mindfulness as moderators. Journal of Family Psychology, 24(4), 380-390. https://doi.org/10.1037/a0019872.

Safran, J., \& Segal, Z. V. (1990). Interpersonal process in cognitive therapy (1st ed.). New York: Basic Books.

Shahar, B., Britton, W. B., Sbarra, D. A., Figueredo, A. J., \& Bootzin, R. R. (2010). Mechanisms of change in Mindfulness-Based Cognitive Therapy for depression: Preliminary evidence from a randomized controlled trial. International Journal of Cognitive Therapy, 3(4), 402-418. https://doi.org/10.1521/ijct.2010.3.4.402.

Shapiro, S. L., Brown, K. W., Thoresen, C., \& Plante, T. G. (2011). The moderation of mindfulness-based stress reduction effects by trait mindfulness: Results from a randomized controlled trial. Journal of Clinical Psychology, 67(3), 267-277. https://doi.org/10.1002/ jclp.20761.

Singh, N. N., Lancioni, G. E., Winton, A. S. W., Singh, J., Singh, A. N., Adkins, A. D., \& Wahler, R. G. (2010). Training in mindful caregiving transfers to parent-child interactions. Journal of Child and Family Studies, 19(2), 167-174. https://doi.org/10.1007/s10826009-9267-9.

Slatcher, R. B., \& Pennebaker, J. W. (2006). How do I love thee? Let me count the words: The social effects of expressive writing. Psychological Science, 17(8), 660-664. https://doi.org/10.1111/j. 1467-9280.2006.01762.x.

Spijkerman, M. P. J., Pots, W. T. M., \& Bohlmeijer, E. T. (2016). Effectiveness of online mindfulness-based interventions in improving mental health: A review and meta-analysis of randomised controlled trials. Clinical Psychology Review, 45, 102-114. https://doi. org/10.1016/j.cpr.2016.03.009. 
Teper, R., \& Inzlicht, M. (2013). Meditation, mindfulness and executive control: The importance of emotional acceptance and brain-based performance monitoring. Social Cognitive and Affective Neuroscience, 8(1), 85-92. https://doi.org/10.1093/scan/nss045.

Van Dam, N. T., Van Vugt, M. K., Vago, D. R., Schmalzl, L., Saron, C. D., Olendzki, A., et al. (2017). Mind the hype: A critical evaluation and prescriptive agenda for research on mindfulness and meditation. Perspectives on Psychological Science, 13(1), 36-61. https://doi. org/10.1177/1745691617709589.

Wachs, K., \& Cordova, J. V. (2007). Mindful relating: Exploring mindfulness and emotion repertoires in intimate relationships. Journal of Marital and Family Therapy, 33(4), 464-481. https://doi.org/10. 1111/j.1752-0606.2007.00032.x.
Weinstein, N., Brown, K. W., \& Ryan, R. M. (2009). A multi-method examination of the effects of mindfulness on stress attribution, coping, and emotional well-being. Journal of Research in Personality, 43(3), 374-385. https://doi.org/10.1016/j.jrp.2008.12.008.

Yusainy, C., \& Lawrence, C. (2015). Brief mindfulness induction could reduce aggression after depletion. Consciousness and Cognition, 33, 125-134. https://doi.org/10.1016/j.concog.2014.12.008.

Publisher's Note Springer Nature remains neutral with regard to jurisdictional claims in published maps and institutional affiliations. 